Prostatic "threads," and flakes of epithelial debris in female urine, were found to give locally positive reactions if caught on the test strip.

\section{Stability of the Strips}

After four hours' exposure in an air oven at $100^{\circ} \mathrm{C}$. the strips showed no difference in sensitivity or colour reaction. Exposure to laboratory air for $\mathbf{2 4}$ hours produced pale-blue discoloration, apparently due to ammonia ; but, surprisingly, such strips reacted normally to urine. Similarly, prior exposure to $\mathrm{HCl}$ fumes apparently caused no permanent damage. Brief exposure to steam or dipping in water did not interfere with subsequent indications, although more prolonged steaming, or washing in running water, resulted in subsequent false positives due to removal of the citrate buffer. For the same reason it appears inadvisable to attempt to use a strip to test more than one urine.

\section{Conclusions}

Albustix is a simple and speedy test for proteinuria, and, although less sensitive than the present tests for urine protein, it appears to be adequately sensitive for routine use.

Variation of urine acidity or alkalinity within physiological limits does not interfere with the results qualitatively, but it slightly affects the quantitative indication.

Gross alkaline fermentation of urine can lead to spurious positive indications, while the addition of acid or toluene as preservatives can lead to false-negative reactions. Natural variations of urine concentration and buffering capacity are unlikely to be sources of error.

Consistent results are dependent on the impregnated portion of the test-strip being completely immersed and quickly removed from the urine. The strip should not be left in urine for subsequent inspection.

False-positive reactions due to non-protein substances have not so far been encountered.

Semi-quantitative recording of results is not recommended, apart from a rough classification such as "negative," "trace," or " positive."

I am grateful to Dr. C. P. Stewart for suggestions and criticisms, and to Mr. D. H. Vobes, of Ames Company (London) Ltd., for a generous supply of albustix, and for information on its composition and mode of action.

\section{REFERENCE}

Harrison, G. A. (1957). Chemical Methods in Clinical Medicine, 4th ed.

On the purchase of hospital equipment, the relevant advisory committee of the British Standards Institution writes: "The B.S.I. enjoys the support of the Ministry of Health in encouraging the purchase by hospitals of equipment conforming to British Standards. At the same time, it is the policy of the Ministry to allow Boards of Governors and Management Committees a good deal of autonomy in the selection of the goods they buy. In consequence there are manufacturers who have co-operated in producing British Standards who state that they rarely receive inquiries for equipment complying with them; on the other hand, hospital officials point out from time to time that they have difficulty in obtaining quotations. Undoubtedly this situation is to a large extent created by tradition and conservatism, manufacturers and users alike preferring to continue, in many cases, with the sale and purchase of commodities to which they are accustomed. There is, moreover, a disappointing lack of awareness that most standards provide alternative types or optional features."-Fourth Report of the Hospital Equipment Standards Advisory Committee (February, 1958), obtainable free of charge from the British Standards Institution, 2, Park Street, London, W.1.

\section{LICHEN PLANUS OF THE MOUTH}

BY

R. P. WARIN, M.D., M.R.C.P.

H. S. M. CRABB, M.D.S., F.D.S. R.C.S.

AND

\section{A. I. DARLING, D.D.Sc., M.D.S., F.D.S. R.C.S. M.R.C.S.}

From the United Bristol Hospitals

The purpose of this paper is to draw attention to lichen planus presenting as a disorder of the oral mucous membrane with minimal or no cutaneous eruption. Fortyfive cases are described.

It is well recognized that lesions in the mouth can often be demonstrated in cases of cutaneous lichen planus. Samman (1956), in a series of 121 cases, recorded mouth lesions in $77 \%$; and, of 227 cases of lichen planus seen in the United Bristol Hospitals from 1949 to 1956 , mouth lesions were present in $51 \%$. However, it does not seem to be generally realized that lichen planus can occur in the mouth without any cutaneous eruption.

\section{Present Series}

During the period 1950-7, 45 patients presenting with mouth lichen planus have been seen by us, 19 being referred to the Dental Hospital and the remainder to the dermatological out-patient department. It is difficult to assess the real incidence, since our special interest in the condition may have attracted some cases which otherwise would not have been referred. The distribution of new cases seen during the period 1950-7 was as follows:

\begin{tabular}{lll|lll|lrl}
1949 & $\ldots$ & 2 & 1952 &. & 5 & 1955 &. & 7 \\
1950 & $\ldots$ & 3 & 1953 & $\ldots$ & 4 & 1956 (firt & 8 \\
1951 &.. & 3 & 1954 & $\ldots$ & 8 & $\begin{array}{l}1957 \text { (first } \\
\text { six months) }\end{array}$ & 5
\end{tabular}

During this period the incidence of cutaneous lichen planus in the same clinical area showed no corresponding rise. Of the cases referred to the dermatological out-patient department, 11 were sent to our colleague, Dr. C. D. Evans, and 15 to one of us (R.P. W.). There is therefore evidence of moderate bias, but, on the other hand, some of the mouth cases may well have been treated by general surgeons, physicians, or dental surgeons, whereas most cases of lichen planus of the skin will be seen at dermatological out-patient departments. Thus for every case presenting in the mouth five or six cases of cutaneous lichen planus have been seen in the same period and clinical area, which gives a rough figure of comparative incidence.

The cases have been followed up at a combined dental and dermatological clinic held monthly. Eight have been observed for over three years; 5 for two to three years; 8 from one to two years; 11 from 3 to 12 months; and 13 on one occasion only. There were 30 females and 15 males. The age distribution was as follows:

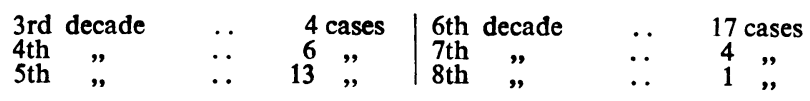

One patient's mother suffered from typical lichen planus confined to the mouth; it developed nine years after the onset in the daughter.

In six patients the condition was symptomless, the mouth lesions being noticed by the doctor or dentist. Twelve complained of roughness or dryness and two of a metallic taste. Thirty had pain at times which was associated with ulceration. Periods of dysphagia occurred in two patientsin one lesions were not noted on oesophagoscopy and the condition was thought by an E.N.T. surgeon to be globus hystericus, while in the other the symptom coincided with 
exacerbations and ulceration of the oral lichen planus. Dentures were worn by 33 patients, but there was no relation between the time of onset and the provision or change of dentures. No association between the extent and distribution of the lesions and smoking habits was noted. Twenty-four patients gave a history of nervous breakdowns, persistent insomnia, or depression, and most patients appeared to be of a nervous sensitive temperament. Seven had had major worries or strain immediately prior to the onset. Four had suffered previously from peptic ulceration.

The areas affected were the inner aspect of the cheek in 34 patients, tongue in 29 , lips in 15 , gum margins in 8 , and palate and fauces in 3 . In these areas the commonest sites for the lesions were opposite the occlusal line on the cheek mucosa, on the dorsum and posterior lateral margins of the tongue, and close to but just short of the gum margins. The lesions consisted of discrete or confluent white spots of pinhead size, white streaks, and, less commonly, white patches up to $2 \mathrm{~cm}$. in diameter, which showed spots or streaks at the edges. The white streaks were often curved, sometimes annular or reticular, and in some cases they were present in the buccal sulcus where the edge of dentures impinged. One patient complained of blisters lasting a few hours, but these were never present on examination. Ulceration occurred at times in 30 patients: on the inner aspect of the cheeks in 19 ; on the tongue in 8 (sides 4, dorsum 3 , and ventral surface 1 ); while in one both cheek and tongue were affected; the gums were ulcerated in one case and lips in another. The ulceration was superficial with a red granular base, although in two cases ulcers on the tongue had a green slough present; they were usually surrounded by white spots or streaks. The ulcers were often opposite a sharp or rough tooth.

The condition completely cleared in only four cases, after 14,14 , and 2 years, and 6 months respectively, and four further cases had minimal relics after $10,5,3$, and 2 years respectively. If the history and the period of observation are taken together the condition was still present after 10 years in 2 patients; between 5 and 10 years in 5 , 3-5 years in 7, and 1-3 years in 15 ; and under 1 year in 8 . When the condition cleared the affected mucosae became normal except on the dorsum of the tongue, where permanent smooth patches usually remained, and at the sites of previous ulceration slight scarring was sometimes apparent.

In one patient an epithelioma developed on the site of recurrent ulceration of the buccal mucosa of 13 years' duration. Five years previous to the epitheliomatous change the patient had received treatment with fractional doses of $x$ rays, but it is unlikely that the small dose $(300 \mathrm{r}$ at $85 \mathrm{kV})$ would have played a part in the initiation of the tumour. One other patient with recurrent ulceration of the buccal mucosa of 10 years' duration developed an epithelioma on the lower lip; no lesions had been noticed on the lip by the patient or by us during previous clinical examination, and the epithelioma was said to have occurred on the site of a cigarette burn.

Minor lichen planus lesions were discovered on the skin in six patients at the first visit, while four others developed such lesions during the period of observation. Similarly, three patients showed anal and vulval lichen planus initially, while 3 developed these later. Thus, including 3 patients who gave a history of previous lichen planus of the skin, 19 of the 45 patients seen had other manifestations of lichen planus in addition to the oral lesions. It is of interest that eight patients showed various patterns of minor eczematous eruptions, one had psoriasis, and one had chronic urticaria during the period of observation.

Confirmatory biopsies were carried out in three cases, but those that were clinically atypical have been excluded from the series.

There is no specific treatment of the condition. Explanation and reassurance, simple psychotherapy, and the use of sedatives and other general supportive treatments have been employed. Some cases improved after treatment with arsenic, aneurine hydrochloride, or injections of cyanocobalamin, but when assessing the value of these treatments it is impossible to exclude the effects of suggestion or the natural fluctuations in the course of the disease. It is clearly important to reduce trauma from sharp teeth or rough dentures, particularly in cases with ulceration. The reduction of secondary infection by chlortetracycline mouthwashes every few hours appeared to help in some cases with severe ulceration.

\section{Discussion}

Lichen planus presenting in the mouth has been recorded by a number of authors. Trautmann (1911) reported 30 cases of lichen planus affecting the mucous membranes of the mouth, nose, and pharynx, while in a further 19 cases skin involvement followed the oral lesions. Fox (1931) described 10 cases of lichen planus confined to the mouth, and Cooke (1954), in an excellent paper, has reported a series of 50 cases. A general review of lichen planus with an account of the oral manifestations has been recorded by Darling and Crabb $(1954,1955)$. The clinical appearance is usually so typical that, provided the examiner is aware of the condition, little difficulty is encountered in diagnosis. Plaques of lichen planus may be difficult to differentiate from leucoplakia, but there are nearly always some typical lichen planus papules or streaks in the vicinity. Patches of lupus erythematosus are often bluish red, with occasionally an adherent slough; additional typical lesions elsewhere can usually be relied on to settle the diagnosis. Moniliasis may be distinguished easily by the redness of the intervening mucosa and the ease with which the white spots or patches may be removed. Cooke has pointed out the importance of recognizing the common white streak, running along the buccal mucosa parallel to the occlusal plane of the teeth, which is a functional keratosis.

The development of carcinoma on the site of lichen planus must be very rare, but, in view of the cases in the present series and of reports in the literature (Montgomery and Culver, 1929; Saad, 1931; Miller, 1947; Carteaud and Stiegler, 1950; Périn et al., 1950, 1951; Marshall, 1951), the possibility cannot be excluded.

It is interesting that lichen planus of the mouth shows much the same features as cutaneous lichen planus, modified to some extent by the moist environment and exposure to trauma. The clinical picture of the disease in respect of age, sex, associated emotional disorders, occasional family history, variation in type of lesion, and prolonged intermittent course is in almost every respect the same for both oral and skin lesions.

\section{Summary}

Forty-five cases are described presenting with lichen planus in the mouth, having no or minimal cutaneous eruption. The incidence, clinical details, and course are discussed. Ulceration occurred in 30 patients, and 2 developed an epithelioma.

We thank Dr. C. D. Evans for referring so many cases to us, and Professor C. B. Perry for his help in the preparation of this paper.

\section{REFERENCES}

Carteaud, A., and Sticgler, J. P. (1950). Bull. Soc. franc. Derm. Syph., 57. 320.

Cooke, B. E. D. (1954). Brit. dent. J., 96, 1.

Darling, A. I., and Crabb, H. S. M. (1954). Oral Surg., 7, 1276.

- (1955). Ibid., 8, 47.

Fox, H. (1931). Arch. Derm. Syph. (Chicago), 24. 1071.

Marshall, J. (1951). S. Afr. med. J., 25, 561.

Miller, J. L. (1947). Arch. Derm. Syph. (Chicago), 55, 153.

Montgomery, D. S. W., and Culver, G. D. (1929). Brit. J. Derm., 41, 45. Perin, L., Ducourtioux, M., and Kritter, H. (1950). Bull. Soc. franc. Derm. Syph., 57, 110.

Sagd - (1951). Ibid., 58, 414

Saad, B. (1931). Ibid., 38, 705.

Samman, P. D. (1956). Brit. J. Derm., 68, 175.

Trautmann, G. (1911). In Die Krankhetten der Mundhöhle und der oberen Luftwege bet Dermatosen, 2nd ed. Bergmann, Wiesbaden. 